\title{
SOBRE CIENCIA Y BRUJERÍA: EL FACTOR CONVENCIONAL DE LAS CREENCIAS
}

\author{
Alejandro BLANCO PASTOR
}

Corría la década de los años sesenta, cuando, enfrentándose al relativismo cognitivo dominante de la época, Robin Horton (1967) propugnó que todos los criterios de racionalidad que constituyen la base de funcionamiento del pensamiento de sentido común se hallan predeterminados en la constitución biológica de la especie humana, por lo que deberían ser los mismos para todos los grupos y sociedades ${ }^{1}$. Desde entonces, y amparándose en esta supuesta universalidad de los criterios de racionalidad del pensamiento ordinario, Horton (1967; 1979 ; 1982; 1993) ha venido sosteniendo con insistencia la tesis de que el valor cognitivo de las creencias mágico-religiosas tradicionales africanas puede ser evaluado con absoluta neutralidad utilizando los criterios que rigen la elección de teorfas en el ámbito de la ciencia occidental. Su idea fundamental es que el pensamiento mágico-religioso tradicional africano viene a ser una manifestación de pensamiento teórico sustancialmente equivalente al pensamiento científico, cuyo cometido natural residiría en la explicación, predicción y control de aquellos fenómenos que el pensamiento ordinario no consigue dominar. El mecanismo explicativo consistiría en ambos casos en postular la existencia de un puñado de entidades y procesos subyacentes a la experiencia con el que se intenta dotar de orden y regularidad a esos fenómenos. Pero el pensamiento teórico no

1 Es obvio que tal idea parecía entonces bastante especulativa y no podía hacer frente a la masiva avalancha de datos sociológicos que operaban en su contra. Tres décadas más tarde, sin embargo, la situación puede estar siendo invertida debido a los esfuerzos que han venido haciendo la psicología y otras ciencias cognitivas para respaldar las tesis innatistas. El interés de todo esto, como veremos a inmediatamente, reside en que Horton pretende utilizar su concepción determinista del sentido común para erradicar el relativismo cultural de la escena antropológica. 
cuenta, según su entender, con unos recursos cognitivos propios e independientes de los que ya tenía disponibles el pensamiento de sentido común, por lo que, para ser aceptadas, sus propuestas respectivas tienen que mostrar que son adecuadas a las exigencias lógicas y empíricas ordinarias, que, al ser universales, servirían para garantizar la neutralidad de su valoración ${ }^{2}$.

En contra de esta idea, intentaré mostrar que, independientemente de la determinación biológica a la que pudieran estar sometidos los criterios de racionalidad del sentido común, el mantenimiento de las creencias mágico-religiosas tradicionales africanas se asienta, evaluativamente hablando, sobre unas convenciones ajenas a ( $y$, en ocasiones, contradictorias con) las que operan en el ámbito científico. Y como dos conjuntos de creencias tan sólo podrían ser neutralmente evaluados si los partidos que los sustentan estuviesen de acuerdo en atenerse a unos criterios de evaluación comunes, el hecho de que esos dos conjuntos de creencias entrañen unas convenciones diferentes quebraría la supuesta neutralidad de su valoración conjunta. Para ello empezaré precisando el papel regulador que cumplen algunas de las que considero que son las convenciones básicas del juego de la ciencia y después elegiré un conocido modelo de pensamiento tradicional africano para poner de manifiesto las divergencias que entraña con respecto a esas convenciones.

\section{Consistencia lógica y adecuación empírica en el juego de la ciencia}

Supongo, en primer lugar, que entre los científicos existe un acuerdo generalizado en que el primer requisito que debe satisfacer cualquier teoría científica es el de la consistencia lógica. La consistencia de las teorías científicas se mide generalmente por los patrones de la lógica estándar, según la cual un enunciado ha de ser verdadero o falso y no puede ser ambas cosas a la vez, pero no conviene olvidar que también se ha llegado a sugerir la necesidad de renunciar a este principio, añadiendo a los dos valores de verdad de la lógica estándar un tercer valor, «indeterminado", para eludir las anomalías de la mecánica cuántica. No obstante, espero demostrar que, tanto si se aceptan como si no se

2 HORTON (1967, 1979, 1982) matiza, no obstante, que, en su nivel teórico, esos criterios están menos claramente definidos y son menos compulsivos en los contextos tradicionales africanos que en el mundo occidental, donde han sido más pulcramente perfilados debido a la incidencia de ciertos factores tecnológicos, económicos y sociales que habrían favorecido su desarrollo sistemático como elementos centrales de la competición interteórica. 
aceptan las lógicas alternativas en el campo de la ciencia, el resultado es igualmente negativo para la tesis de Robin Horton.

En cuanto a la adecuación empírica diré que, si bien dudo mucho de que se pueda satisfacer en la forma clásica de teoría dura de la correspondencia ${ }^{3}$, debo admitir que el afán de la ciencia por obtener un conocimiento preciso de la realidad la invita a contrastar empíricamente las teorías a través de sus implicaciones más fácilmente negociables, que son, después de todo, las que se expresan en un lenguaje (relativamente) observacional ${ }^{4}$. Es este procedimiento el que autoriza a mantener en la ciencia aquello de que el hombre propone y el mundo dispone. Pero, como dice Quine, el mundo no dispone más que "a través de veredictos holofrásticos que sólo afiaden un sí o un no a las oraciones observacionales que expresan las predicciones del hombre» (1990:63). Y aun cuando, como es sabido, los resultados afirmativos de las contrastaciones empíricas no sirven para verificar concluyentemente una teoría, los resultados adversos abren al menos la posibilidad de su refutación ${ }^{5}$, siendo la importancia que se concede a esta eventualidad en el ámbito científico lo que hace que las teorías se vean permanentemente involucradas en un proceso activo de retroalimentación con el mundo externo que no es de obligado cumplimiento para otras clases de discurso entre cuyos fines no se encuentre la representación objetiva de la realidad.

Esto es lo que, a diferencia de Horton, yo supongo que sucede con los sistemas mágico-religiosos tradicionales: que no pretenden representar el mundo

3 Entiendo por "teoría dura de la correspondencia» la que parte de la concepción ortodoxa del significado y afirma que el significado literal de una sentencia descriptiva determina por sí mismo su valor de verdad: la sentencia es verdadera si lo que describe es el caso en realidad. La razón de mi recelo hacia esta caracterización de la adecuación empírica radica, como se puede suponer fácilmente, en que ningún lenguaje, ni siquiera el lenguaje cientifico, puede reproducir de manera directa, neutral e isomórfica la realidad objetiva.

4 Evidentemente, si lo que se considere observacional puede variar de un caso a otro, la relevancia intersubjetiva de las observaciones quedará siempre reducida al círculo de los testigos teóricamente competentes.

5 Incluso reconociendo con QUINE que, debido a la difusividad de la significación empirica (1970), la falsedad de cualquier predicción cientifica siempre puede ser abortada realizando los ajustes necesarios en otras partes de la teorla que no estén tan directamente relacionadas con la hipótesis contrastada o incluso fuera de la teoria misma (QUINE, 1953), aun podemos seguir suponiendo que los resultados adversos de las contrastaciones no pasan, en general, desapercibidos dentro del ámbito científico. Si en unas ocasiones la economía hace aconsejable responder ante ellos mediante la redefinición de algunos términos lingüísticos, en otras ocasiones su impacto puede forzar el abandono de la hipótesis contrastada o incluso el rechazo de la teorfa completa que la motivó (aunque esto sólo se produzca si se cuenta con otra teorla alternativa considerada más precisa o más útil). 
siguiendo criterios objetivos, y por consiguiente no creo que ni la lógica ni el mundo externo ejerzan una presión demasiado fuerte sobre ellos. Pero si Horton estuviese en lo cierto deberían ejercerla, al menos en una medida suficiente para evitar que las contradicciones lógicas o empíricas demasiado evidentes llegasen a ser recalcitrantes. En las próximas páginas intentaré demostrar que éste no es el caso, pero haré todavía un par de precisiones antes de exponer los hechos más directamente relacionados con esta cuestión.

En primer lugar, debo hacer referencia a la distinción que separa la vertiente normativa de los criterios de racionalidad como guía ideal para la mejora del conocimiento científico, por un lado, del comportamiento real de los científicos, por otro. Para no idealizar el comportamiento de los científicos, admitiré que a menudo tienden a ser poco críticos con sus teorías y que la confianza depositada en ellas cuando han resistido la presión de los hechos durante largo tiempo puede alimentar su deseo de protegerlas. Pero ahora no me preocupa tanto la disposición de los científicos a exponer sus teorías a la falsación y la crítica cuanto me preocupan las reglas que definen el juego de la ciencia y, sobre todo, si podemos o no suponer que las creencias mágico-religiosas tradicionales están sujetas a esas mismas reglas, pues, evidentemente, no es el comportamiento particular de los cientificos por sí mismo el que hace "objetivas" (científicas) a las teorías, sino la crítica intersubjetiva a la cual la institución científica como un todo las somete. Y para que esto pueda llevarse a cabo es necesario que a quienes practican el juego de la ciencia se les suponga comprometidos con las reglas que lo definen, pues de otro modo no existiría la ciencia, ya que ningún juego puede tener una existencia al margen de las normas compartidas que lo concretan como una actividad específica ${ }^{6}$. Así que para llegar a alcanzar los objetivos aquí perseguidos me basta con poder afirmar lo siguiente: sea cual sea la disposición de los científicos a exponer sus teorías a la crítica pública, su compromiso con los criterios lógicos y empíricos se considera imperativo, por eso, cuando se les cuestiona sobre la conformidad de sus teorías con dichos criterios, los cientificos tienden a buscar respuestas adecuadas para satisfacerlos, pues ésta

6 SeArle (1965:433) llamaba kreglas constitutivasm a este tipo de reglas que crean la posibilidad misma de practicar un juego. Su caracteristica frente a otros tipos de reglas, como son las «reglas regulativas", que simplemente "regulan una actividad preexistente, una actividad cuya existencia es lógicamente independiente de la exletencia de las reglas*, es que ulas reglas constitutivas constituyen (aunque también regulan) una actividad cuya existencia es lógicamente dependiente de las reglass. La distinción original proviene de RAwLS, J. 1955, "Two concepts of Rulesw. The Philosophical Review. 
es la única manera que tienen de seguir dentro del juego, ya que de otro modo se diría que han renunciado tácitamente a su participación ${ }^{7}$.

En segundo lugar, diré que tampoco considero necesario exigir que los pueblos tradicionales africanos sometan sistemáticamente sus creencias mágicoreligiosas a pruebas experimentales controladas de un modo tan refinado como lo hace la ciencia actual, para conceder a Horton que los criterios científicos pueden ser considerados importantes para su validación. Bastaría con encontrar una clara preocupación por evitar las contradicciones lógicas entre las expresiones que conforman sus sistemas mágico-religiosos y un decidido interés de los creyentes por acomodarlas empíricamente a sus observaciones más o menos rutinarias e intersubjetivas, para dejar abierta la posibilidad de que la tesis de la equivalencia entre ambos modos de pensamiento teórico fuese correcta en este aspecto. Creo, sin embargo, que hay casos recalcitrantes que permiten afirmar que esas creencias deberian ser puestas en entredicho (bien por su inconsistencia lógica, bien por chocar frontalmente contra los hechos o bien por ambas cosas a la vez) si los criterios de la ciencia tuviesen algo que ver en el procedimiento de su legitimación. Para ilustrar todo esto me remitiré a las creencias de los azande en la brujería y los oráculos.

\section{Brujería y oráculos entre los azande}

Como todos sabemos gracias a la espléndida monografla de Evans-Pritchard (1937), los azande están convencidos de que todos los sucesos desafortunados

7 Evidentemente, alguien puede pasar por alto las reglas regulativas imperantes en un juego sin renunciar a seguir jugando, pero no puede saltarse las reglas constitutivas, so pena de abandonar la práctica del juego en cuestión. Así, por ejemplo, no cumplir con las reglas de cortesía durante una partida de ajedrez puede ser motivo de reproche, pero mientras uno se acomode a las reglas constitutivas que definen la práctica del juego, nadie dirá que no juega al ajedrez. Por el contrario, si alguien se empería en mover los trebejos a su antojo sin atenerse a lo que mandan las reglas constitutivas que definen la práctica del juego, todos din'amos que no juega al ajedrez. El juego de la ciencia es, sin duda, mucho más complejo que el juego del ajedrez. Por lo que alguien podría mantener inadvertidamente una teoría que encerrase una contradicción, o podría ser incluso que mantuviese conscientemente una teoría contradictoria porque no encontrase la manera apropiada de solventarla con la información que tuviese disponible, $y$ no dirfamos por eso que ha renunciado a la práctica científica. Lo que, sin embargo, no dirfamos en ningún caso es que practica el juego de la ciencia si muestra desinterés por la consistencia lógica o por la adecuación empírica de sus teorías. 
importantes se deben siempre a la acción de algún brujo. Según los azande, cualquier vecino suyo puede ser brujo a sabiendas o sin saberlo él mismo, pues la condición de brujo tan sólo reside en tener materia de brujería en el cuerpo. El caso es que a un brujo le basta con desear consciente o inconscientemente el mal a alguien para que a éste le sobrevenga una desgracia. Por eso, cuando un zande se encuentra ante la adversidad, intenta descubrir al brujo que origina su infortunio y le pide que renuncie a seguir causándole daño. El procedimiento consiste en ofrecer al supuesto brujo el ala de un pollo, sobre la cual éste último escupe para demostrar públicamente su disposición a enfriar la materia de brujería que pudiera tener en su cuerpo.

La materia de brujería es una sustancia, bien conocida por los azande, que se localiza en el vientre de los brujos y que se hereda por vía patrilineal entre los varones y por vía matrilineal entre las mujeres. Como el clan zande es un grupo de personas emparentadas por línea del varón, si se demuestra mediante la autopsia que un hombre es brujo, entonces, según los criterios de la lógica estándar, todos los miembros varones de su clan habrían de ser lógicamente brujos también. Sin embargo, llegado el caso, los azande se niegan a aceptar las consecuencias lógicas de este razonamiento. Por lo que no es de extrafiar que se haya escrito en abundancia sobre los criterios lógicos que rigen las creencias azande relacionadas con la brujería. Así que volveré enseguida sobre esta cuestión, pero antes quiero hacer referencia a las consultas oraculares de los azande.

Los azande tienen una gran fe en sus oráculos, sobre todo en el oráculo del veneno, al que acuden siempre que se ven presa de alguna desdicha para descubrir al brujo responsable. La consulta consiste en hacer tragar un veneno especial (benge) a un pollo, mientras se pide al oráculo que conteste afirmativa o negativamente a la pregunta de si el zande $x$ es el brujo causante de su infortunio. La respuesta del oráculo se manifiesta en la muerte o en la supervivencia del pollo, dependiendo de cómo se haya formulado la pregunta. Así, utilizando un pollo tras otro, los azande van descartando sospechosos hasta encontrar al verdadero culpable de su desgracia.

El oráculo del veneno también puede ser consultado sobre otras cuestiones, y en general los azande le preguntan con asiduidad sobre cualquier asunto de su interés. Le hacen consultas sobre la cosecha para saber si está a salvo; le consultan antes de desposar a una mujer para saber si conviene tomarla por esposa; le consultan la víspera de una cacería para saber si hay algún peligro oculto; o le consultan antes de construir una cabaña para saber si el momento y el 
lugar elegidos son los adecuados. Si el oráculo del veneno dice que no hay peligro en ello, los azande acometen estas empresas conforme las habían planeado y en caso contrario se abstienen de seguir adelante con sus planes. En algunos casos, por último, la consulta al oráculo del veneno es prácticamente de obligado cumplimiento, en especial cuando el resultado puede tener consecuencias públicas, como son las acusaciones de brujería o de adulterio.

La idea de la unicidad de la lógica y la idea de la fuerza de la lógica

Nos preguntamos ahora si los criterios cientificos son importantes para el mantenimiento de las creencias azande. Por lo que respecta a la consistencia lógica, el asunto es ciertamente complejo. Desde que Evans-Pritchard publicase su monografla en la década de los años treinta, las interpretaciones de la lógica zande se han incrementado permanentemente, llegando éstas con frecuencia a conclusiones contradictorias entre sí. Pero dicha monografia sigue siendo la fuente original de los datos y, en principio, de ella desprende una lectura negativa para la tesis de Robin Horton, pues muestra una clara falta de simetría entre la preocupación por los criterios lógicos occidentales, empleados con rigor por el antropólogo, y la poca disposición de los azande a satisfacer esos criterios en sus respuestas. Buena prueba de ello es que los azande se negasen con frecuencia a conceder sentido a las preguntas de Evans-Pritchard, preguntas que, como veremos en adelante, para nosotros son tan sensatas como elementales, pero que a menudo ellos encontraban fuera de lugar.

No obstante, algunos de los presupuestos de partida asumidos por EvansPritchard han contribuido a levantar cierta polémica respecto a la preocupación lógica de los azande. Evans-Pritchard estaba convencido de que existe una auténtica racionalidad universal y tenía también una clara tendencia a identificar esa racionalidad con la racionalidad científica. Esto le llevó a suponer que los azande habrian atendido a sus argumentos de no haber sido por el misticismo que envolvia sus creencias en la brujería.

En cuanto al hecho de que los azande no siempre aceptasen que si la brujería se hereda linealmente entonces en el clan de un brujo todos son brujos, Evans-Pritchard lo explicaba diciendo que los azande se concentran en los casos concretos de brujería y nunca se plantean la cuestión desde una perspectiva 
general $^{8}$. Sin embargo, añadía que, si bien "la brujería explica las circunstancias concretas y variables de un acontecimiento y no las generales y universales" (pág. 88), cuando se les expone la cuestión de un modo general, los azande «entienden el sentido de este razonamiento" pero no aceptan sus conclusiones porque "de hacerlo así pondrían en contradicción toda la noción de brujería" (pág. 51). De ahl que los azande, acosados por las preguntas de EvansPritchard, sintiesen, según él, la necesidad de justificar su incoherencia con argumentos que no comprometiesen la noción de brujería. De donde extrala que son "las posteriores elaboraciones de la creencia" las que «liberan a los azande de tener que admitir lo que a nosotros nos parecen las consecuencias lógicas de la creencia..." (Ibid.).

David Bloor (1976: Cap. 7) ha señalado con precisión que el análisis de Evans-Pritchard encierra dos ideas fundamentales: primera, que hay una contradicción en las creencias de los azande, tanto si ellos la ven como si no; $y$, segunda, que si los azande admitiesen el error, una de sus instituciones sociales más importantes se volvería insostenible, por lo que persistir en el error les resultaría vital ante la amenaza de enfrentarse a un cataclismo social. "La primera idea es la creencia en la unicidad de la lógica; la segunda idea es la creencia en la fuerza [potency] de la lógican (pág. 139). (La lógica es poderosa porque la confusión lógica puede provocar la confusión social.) Si este análisis de Bloor es relevante para nosotros, no lo es solamente porque nos sirve para descubrir el sesgo teórico-cultural de los informes de Evans-Pritchard, sino porque esas dos ideas son también fundamentales para la tesis de Robin Horton. La idea de la unicidad de la lógica es fundamental para su idea de la unidad de la racionalidad humana y la idea de la fuerza de la lógica lo es tanto para esa idea como para la idea de que los criterios de aceptación de las creencias tradicionales africanas son los mismos criterios que rigen la aceptación de las teorías científicas. En el próximo apartado discutiré la posibilidad de mantener la validez conjunta de ambas ideas en relación con el caso de la brujería zande, pero antes conviene hacer algunas consideraciones al respecto.

Evans-Pritchard encontraba, por un lado, que la lógica de los azande es en general impecable, aunque, por otro lado, negaba la racionalidad de la creencia

8 «Los azande -escribe Evans-Pritchard- no perciben la contradicción que nosotros observamos porque no tienen interés teórico por la cuestión y las situaciones en que se manifiestan sus creencias en la brujería no les obligan a plantearse problemasw, pág. 51 . 
en la brujería a partir de su identificación de "la racionalidad» con la racionalidad occidental. Evans-Pritchard mantenía esta posición respecto a las creencias azande porque consideraba que «las nociones lógicas son aquellas en las que, de acuerdo a las reglas del pensamiento, las inferencias serían verdaderas si las premisas fuesen verdaderas, siendo irrelevante la verdad de las premisas", mientras que sostenía que "las nociones científicas son aquellas acordes con la realidad objetiva, tanto en lo que se refiere a la validez de sus premisas como a las inferencias extraídas de sus proposiciones" ${ }^{9}$. Y dado que, según Evans-Pritchard, las creencias azande hacen referencia a todo un universo de fuerzas y poderes místicos, cae por su propio peso que no son acordes con la realidad objetiva.

En su conocida crítica de 1964, Peter Winch señaló que la definición de Evans-Pritchard presenta ciertos problemas derivados de considerar racionales para todos los discursos las nociones "acordes con la.realidad objetiva" suponiendo que esa realidad es independiente del lenguaje que la describe (pág. 81). El sentido del lenguaje, decía Winch, no depende de una realidad independiente: lo que es real y lo que no es real está determinado por la forma en que esa distinción opera en el lenguaje empleado y por su universo del discurso (págs. 82-83). Consiguientemente, todos los sistemas constituyen universos de discurso coherentes, en función de los cuales se puede discernir una concepción de la realidad y establecer las vías para decidir qué creencias están de acuerdo con esa realidad (Ibid.).

En cuanto al caso concreto de los azande, Winch coincidía con EvansPritchard en que el modo de poner a salvo los pronunciamientos de los oráculos frente a cualquier conflicto con la experiencia y su negativa a considerar contradictoria su actitud hacia la heredabilidad de la brujería, venían a demostrar que sus creencias no operan a un nivel "teórico» equivalente al de la ciencia. Es decir, que «Las nociones azande sobre la brujería no constituyen un sistema teórico por cuyo medio los azande intenten obtener un entendimiento quasi-cientifico del mundo" (pág. 93) ${ }^{10}$. Pero, por eso mismo, pensaba Winch, no se puede juzgar la racionalidad de esas creencias al amparo de los criterios científicos, pues se

9 Evans-Pritchard, E. E. 1935, "Science and Sentiment", Bulletin of the Faculty of Arts, Universidad de Egipto. Citado en WINCH 1964, «Understanding a Primitive Society», Ameritan Philosophical Quaterly I; reimp. en B.R. Wilson (ed.) 1970, Rationalitys pág. 80.

10 "Nótese - aclara Winch en nota al pie, Ibid. - que yo no he dicho que las concepciones azande sobre la brujería no tienen nada que ver en absoluto con el entendimiento del mundo. $\mathrm{El}$ asunto es que aquí está involucrada una forma diferente del concepto de entendimientow. 
trata de sistemas independientes, con realidades independientes y criterios de racionalidad independientes. De ahí que sea «el europeo, obsesionado por presionar el pensamiento zande hacia donde éste no iría naturalmente - hacia la contradicción-, quien es responsable del malentendido, no el zande" (Ibid.).

Precisamente, cuando Evans-Pritchard encontró que las creencias de los azande eran coherentes si se tenían en cuenta las asociaciones que efectuaban los azande, y que sin embargo los criterios más exigentes de la racionalidad occidental no eran aceptados por ellos, él mismo supuso que se encontraba ante un problema de acoplamiento entre lenguajes o culturas ${ }^{11}$. Pero, atrapado en la red de pensamiento occidental y deslumbrado por los cánones de la racionalidad científica, Evans-Pritchard fue tan incapaz de poner en cuestión la universalidad de sus propios criterios de racionalidad como, desde su perspectiva, lo eran los azande para dudar de la validez de sus creencias.

Peter Winch sugirió que Evans-Pritchard habría salido mejor de su enredo si, en lugar de aferrarse a una concepción de la relación entre el lenguaje, la lógica y el mundo como la que habla desarrollado Wittgenstein en el Tractatus, hubiese derivado hacia posiciones más relativistas con respecto a los conceptos de realidad implicados en los diferentes discursos y hubiese aceptado que puede haber una diversidad de reglas que definan contextualmente su corrección; es decir, si hubiese adoptado unas ideas más parecidas a las que llegaron a constituir la posterior noción wittgensteiniana de los juegos (pág. 91).

Ciertamente, la solución propuesta por Winch puede parecer más prometedora en este caso. Pero, como observa Bloor (pág. 140), aunque Winch rechaza con su análisis la idea de la unicidad de la lógica que sostenía Evans-Pritchard, tampoco él llega en ningún momento a poner en cuestión la creencia en la fuerza de la lógica. De hecho, Winch construye su argumento bajo el supuesto de que los azande habrían encontrado en el razonamiento de Evans-Pritchard una amenaza para sus instituciones si la racionalidad de la

11 "Cuando en ciertos momentos intenté poner en duda la fe zande en su oráculo del veneno, a veces tropezaba con afirmaciones a bocajarro, a veces con alguna de las elaboraciones secundarias de la creencia a propósito de cualquier situación concreta que provocara escepticismo, a veces con una educada compasión, pero siempre con un enredo de obstdculos lingǘsticos, pues no pueden expresarse bien en su lengua las objeciones que no formula su cultura» (pág. 299. La cursiva es mía). «O bien, planteándolo de otra forma, razonan excelentemente en el lenguaje de sus creencias, pero no pueden razonar fuera ni en contra de sus creencias, porque no tienen otro lenguaje en que expresar sus pensamientosn (pág. 314). 
brujería no fuese diferente de la racionalidad cientifica, lo que deja ver su acuerdo implícito con la idea de la fuerza de la lógica.

Esta apreciación de Bloor parece correcta. Mas, por lo que respecta a sus efectos sobre la tesis de Robin Horton, sus implicaciones son igualmente negativas, pues, como he dicho anteriormente, basta con demostrar que una de las dos ideas en cuestión no es sostenible (sea ésta la idea de la unicidad de la lógica o sea la idea de la fuerza de la lógica) para que su tesis sea igualmente insostenible. Asl que voy a mostrar a continuación que el ejemplo zande nos obliga a negar la validez de, al menos, una de esas dos ideas.

La idea de la unicidad de la lógica y la idea de la fuerza de la lógica a la luz del caso zande

Empezaré este apartado comentando diversos intentos de solventar las incoherencias que presentan las creencias de los azande cuando se interpretan al amparo de la(s) lógica(s) científica(s) para poner al descubierto que conducen a un fracaso sistemático y después dejaré abierta la posibilidad de elegir entre el rechazo de la idea de la unicidad de la lógica o el rechazo de la idea de la fuerza de la lógica.

En un doble esfuerzo por convencernos de que las creencias azande son lógicamente equiparables a las teorías científicas y dar así apoyo a la tesis de Robin Horton sobre la equivalencia entre ambos modos de pensamiento, David Cooper (1975) adujo que la contradicción entre la afirmación de la transmisión lineal de la Brujería y la negación de que en el clan de un brujo todos son brujos, quedarla disipada si encontrásemos que los azande adaptan sus razonamientos a la lógica trivalente utilizada por Reichenbach para disolver las anomalías de la mecánica cuántica ${ }^{12}$. Si se pudiese confirmar que los

12 No creo que esta forma de defensa de su intelectualismo agrade demasiado al propio Horton, pues, de ser aceptada, salvaría una parte de la tesis de la equivalencia entre las religiones tradicionales africanas y la ciencia occidental a costa de socavar el sustento más fuerte de la misma, ya que obrarla a favor de la revisabilidad de los principios lógicos y por lo tanto en contra de la determinación biológica de ese núcleo duro de racionalidad universalmente compartido que representa el sentido común. El hecho de que Robin Horton no aluda en ningún momento al artículo de Cooper en la reformulación que efectuó de su tesis en 1982 hace que aumente el grado de mi sospecha. 
azande asignan el valor «indeterminado" a la afirmación «los parientes de un brujo son todos brujos", dacia Cooper, la conclusión dejarla de ser contradictoria (pág. 245) y el problema de su coherencia lógica quedarla resuelto.

Pero, como bien sabe Cooper, los motivos de Reichenbach para decantarse por una lógica trivalente en el caso de la mecánica cuántica se debían a que dentro de la lógica estándar resulta imposible asignar valores de verdad a dos proposiciones complementarias. Y dos proposiciones son complementarias cuando la prueba experimental de la verdad de una de ellas hace imposible en principio la prueba experimental de la verdad de la otra. Por lo tanto, para aceptar que los azande utilizan una lógica trivalente, deberíamos encontrar que, según los criterios azande, algunas de sus afirmaciones son incontrastables e indeterminadas. Sin embargo, las pruebas aportadas por Cooper en favor de esta hipótesis son indirectas y se basan, principalmente, en el hecho de que los azande no se sientan obligados a rechazar como falsas las premisas que, de conformidad con la lógica estándar, llevan a una contradicción. Una actitud propia, según Cooper, de quienes manejan las proposiciones individuales como si fuesen indeterminadas (pág. 251).

En otro intento por demostrar que las creencias azande son coherentes utilizando la lógica occidental, pero beligerante con la idea de extender la lógica trivalente a las creencias de los azande, Merrilee H. Salmon (1978) acusó a Cooper de no haber establecido adecuadamente la distinción entre uno directamente contrastable" e uincontrastable en principio» (pág. 447). A1 hilo de un pasaje de Putnam citado por Cooper, Salmon le recordaba que el valor de verdad "indeterminado» de una sentencia indica algo más que el desconocimiento de si esa sentencia es verdadera o falsa: «Decir que una sentencia es indeterminada entraña que la sentencia nunca será verificada o falsada" (pág. 448). Esto es precisamente lo que sucede con los fenómenos cuánticos, que se plantean en sentencias que describen ciertos eventos únicos, como el momento y la posición de una partícula, que, de acuerdo con ciertas leyes físicas actuales, no podrán ser jamás conjuntamente verificadas o falseadas suceda lo que suceda en el futuro. Sin embargo, la sentencia zande "los parientes biológicos de un brujo son todos brujos" no se refiere a eventos particulares que coinciden en un momento particular haciendo imposible su contrastación conjunta, sino que tiene una forma lógica general para la cual no existe ninguna ley que pueda asegurar -ni a nosotros ni a los azande- que no sea verificable of falsable en principio (pág. 449). 
Aunque encuentro acertadas estas apreciaciones de Salmon, creo que la forma más directa y rotunda de poner al descubierto las carencias de la hipótesis de Cooper consiste en demostrar que los azande no consideran «indeterminado" el valor de verdad de la sentencia «los parientes de un brujo son todos brujosw. Esto se apreciará bien si dirigimos la atención hacia las elaboraciones secundarias de esa creencia, realizadas por los azande, según Evans-Pritchard, para evitar enfrentarse a lo que serien sus. consecuencias lógicas, pues ni siquiera en esos casos los azande amenazados de Brujería por consanguinidad intentan arrojar dudas sobre su verdad. Si observamos con atención lo que sucede cuando un zande $\mathrm{x}$ se enfrenta con el razonamiento: P1 "los parientes de un brujo son todos brujos», P2 «a es un brujo", P3 «a es pariente de b», C «b es un brujo", veremos que estando él en la posición de b no suele rechazar ni la verdad de P1 ni la verdad de P2 (si así ha quedado establecida mediante la autopsia) ni, lo que es más importante, la relevancia de éstas para el establecimiento de C. Lo que en estas circunstancias tiende a rechazar el zande es P3; es decir, tiende a negar su relación de parentesco con el brujo, alegando, generalmente, y a veces con suma vehemencia, que el brujo era bastardo, como se deduce del siguiente pasaje de Evans-Pritchard:

"Si se demuestra que un hombre es brujo más allá de toda duda, los parientes, para demostrar su inocencia, pueden utilizar el mismo principio biológico que parecía abocarlos al descrédito... Dicen que era bastardo, pues entre los azande un individuo siempre es miembro del clan de su genitor y no del de su pater, y me relataron que pueden obligar a la madre, si vive, a decir quién fue su amante, golpeándola y preguntándole..." (pág. 50).

Ya digo, demasiada vehemencia para dejarnos convencer por demostraciones indirectas de que los azande consideran "indeterminado" el valor de verdad de P1. Lo que se demuestra más bien es que no dudan de que el valor de verdad de tal afirmación es "verdadero». Y digo más, la verdad de la heredabilidad de la Brujería no es solamente afirmada por los azande, sino invocada por ellos mismos en su propia defensa cuando les conviene, aportando incluso las pruebas empíricas adicionales necesarias para que se acepte también la verdad de las premisas particulares del razonamiento y en consecuencia sea lógicamente ineludible la conclusión ${ }^{13}$. Por lo cual, si esta fuese la historia completa, habríamos

13 "Con más frecuencia, simplemente hacen una declaración de que el brujo debe haber sido bastardo, puesto que ellos no tienen brujeria en sus cuerpos y por tanto él no puede ser uno 
de admitir que los azande se contradicen en aquellas otras ocasiones en las que, habiéndose demostrado la existencia de materia de Brujería en el vientre de un zande, niegan que todos los demás miembros de su clan sean brujos, o cuando admiten que también pueden ser brujos los parientes de un zande con el vientre limpio de Brujería ${ }^{14}$, pues si el valor de verdad de P1 fuese «indeterminado», por su forma lógica general, habría de serlo para todos los casos, y esto, como acabamos de ver, no es así.

Pero Salmon no recurre a este tipo de argumentos en su critica de la hipótesis de Cooper porque persigue la demostración adicional de que la contradicción en cuestión puede ser eludida sin renunciar a la idea de que el razonamiento de los azande se ajusta plenamente a los patrones de la lógica estándar ${ }^{15}$. Partiendo del hecho de que cualquier zande puede tener materia de Brujería pero no es considerado brujo si la materia está fría (si no está causando mal a nadie), Salmon plantea que los azande tienden a utilizar el término «ser brujo" en dos sentidos distintos: un sentido de «ser brujo» sería el de tener materia de Brujería y el otro sería el de utilizar la Brujería contra alguien. Y, efectivamente, si se utilizasen inadvertidamente estos dos sentidos del término en un mismo razonamiento, se estarla cometiendo una falacia por equivoco, según podrían apreciar los azande menos versados en lógica.

Es cierto que en el informe de Evans-Pritchard se aprecia el doble uso por parte de los azande del término en cuestión. Pero debemos tener en cuenta que es Evans-Pritchard quien detecta la contradicción de los azande y no los azande quienes acusan a Evans-Pritchard de inconsistencia por equivoco. No creo,

de sus parientes, y pueden apoyar esta opinión citando casos de parientes suyos en que la autopsia ha demostrado que estaban libres de brujeríam (pág. 50). En otro pasaje, Evans-Pritchard nos dice además que un zande que haya sido acusado repetidas veces de brujería puede pedir que el día de su muerte se le practique la autopsia para mantener "el honor de su linajen, e incluso puede pedir que se realice la operación sobre un hijo muerto prematuramente, pues al ser la materia de brujería hereditaria upuede descubrirse en el vientre de un pariente varón próximo con tanta seguridad como en el vientre del propio brujon (págs. 65-66). A pesar de todo, Evans-Pritchard anade: «Es improbable que los demás acepten esta disculpa, pero no se les pide que la acepten ni; que la rechacenn (Ibid.).

14 «Otra vez podríamos razonar que si la autopsia descubre que un hombre está inmune de materia de brujería, todo su clan debe también estar inmune, pero los azande no actúan como si fueran de esta opinión” (pág. 50).

15 Aunque Salmon reconoce como una cuestión de hecho que «algunos patrones de pensamiento mistico y religioson rechazan abiertamente los krequisitos de consistencian, afirma que no hay evidencia de que las creencias azande sobre la brujería sean de este tipo (pág. 449). 
por otra parte, que nadie que haya leído su monografía encuentre más motivos para dudar de la perspicacia lógica de Evans-Pritchard que de la corrección lógica de los azande en cuestiones de Brujería, y encuentro más que dudoso que Evans-Pritchard hubiese cometido un error tan evidente ${ }^{16}$. Por lo que lo mejor será obviar la propuesta de Salmon y aceptar que si se juzga la Brujería zande con los cánones de la lógica cientifica no parece posible que pueda ser razonablemente absuelta del cargo de contradicción. Así que o bien concluimos que la lógica de la Brujería zande es diferente de la lógica científica o bien suponemos que a los azande la consistencia lógica de su noción de Brujería les trae sin cuidado. Si en relación con este caso se debe renunciar a la idea de la unicidad de la lógica o a la idea de la fuerza de la lógica (o, tal vez, a las dos), es una cuestión que habrán de resolver los antropólogos a través de ulteriores indagaciones que, partiendo de unos presupuestos más flexibles, vengan a completar los informes originales de Evans-Pritchard. $\mathrm{Y}$ aun cuando por la dependencia contextual que muestra la lógica respecto a los criterios convencionalmente asumidos para dar y aceptar razones en cada cultura (o mejor en cada juego de lenguaje, incluidos algunos juegos de lenguaje occidentales), podríamos sentirnos inclinados a negar la idea de la unidad de la lógica científica con la lógica zande - al menos en lo que atañe a la lógica de la Brujería-, lo más sencillo sería aceptar la propuesta de debilitar la creencia en la fuerza de la lógica ${ }^{17}$. A fin de cuentas, los reproches de inconsistencia lógica y falta de acuerdo con la realidad pueden tener algún efecto sobre la aceptación

16 Más bien, al contrario, pienso que es la creencia de Salmon en el poder de la lógica y su deseo de ajustar la lógica zande a sus propios criterios de validez argumental lo que la empuja a elaborar esas interpretaciones alternativas a la de Evans-Pritchard. Esto sólo demuestra que, si bien en toda interpretación intercultural el principio de caridad es un recurso metodológico adecuado, también lo es el beneficio de la duda, e insistir a toda costa en que los razonamientos de los otros son en todos los casos conformes a nuestros criterios ideales de racionalidad puede tornar una caridad razonable en caridad excesiva, ya que, como dice QUINE (1959:269), podemos "admirarnos tanto de la inescrutabilidad de la mente de los indígenas como del estrecho parecido entre ellos y nosotros, según que hayamos sido incapaces de encontrar una buena traducción o, por el contrario, hayamos hecho un trabajo más detallado, hasta leer nuestros propios usos lingüísticos provinciales en el lenguaje de la junglan.

17 «Después de todo, a ninguno se nos escapa la facilidad con la que también en Occidente podemos encontrar patrones de "pensamiento mistico" - por decirlo al modo que Evans-Pritchard heredase de Lévy-Bruhl- ni tampoco se nos escapa la gran semejanza que exhibe este pensamiento con el pensamiento mágico-religioso tradicional africano. Una muestra detallada de los paralelismos existentes entre los enigmas lógicos de los sistemas religiosos tradicionales y occidentales, realizada al amparo de los conceptos de *unidad-en-la-dualidad", "multipresencia" y uparticipación mística", procedentes de Lévy-Bruhl, puede encontrase en Skorupski (1973:106-113). 
de las creencias en el caso de la ciencia porque estos criterios se asumen como parte de las reglas constitutivas del juego y en consecuencia se imponen sobre quienes deciden practicarlo. Pero enfrentados a otros juegos de lenguaje en los que no parece existir un compromiso, aunque sea ideal, con tales criterios, no veo cómo se puede forzar a nadie a dudar de aquello en lo que cree, sobre todo si lo creído cuenta a su favor con la fuerza socialmente sancionada de la tradición, como sostendré en el próximo apartado.

\section{La relevancia empírica de las predicciones oraculares entre los azande}

Tal vez la distinción más importante entre el modo de legitimación de las creencias mágico-religiosas tradicionales y el modo de legitimación de las teorías cientificas sea precisamente la que remite a la fuente de autoridad de sus discursos respectivos. Mientras que la fuerza discursiva de la ciencia reside en el compromiso asumido con los criterios lógicos y empíricos, la fuerza del discurso mágico-religioso tradicional remite a la autoridad de la tradición ${ }^{18}$. Pero este proceder de los pueblos tradicionales africanos, que a muchos nos sugiere una clara falta de simetría entre su modo de pensamiento mágico-religioso y el modo de pensamiento científico, para Horton no es tan relevante como pudiera parecer en primera instancia. Según la interpretación más extensa que él hace (1982:239-240) de la forma de legitimación de las creencias tradicionales, afirmar que «si esas creencias han llegado generación tras generación hasta nosotros, entonces han de ser válidas» implica el reconocimiento tácito de que tales creencias son adecuadas porque han cumplido satisfactoriamente las funciones de explicación, predicción y control de los fenómenos naturales en un sinfin de situaciones anteriores: "Dicho en pocas palabras, las creencias no son precisamente aceptadas porque se las considere de la edad de oro, sino porque se las considera contrastadas en el tiempo" (Ibid.).

18 Como sabemos, la legitimidad de las creencias tradicionales está generalmente asociada a la narración de un extendido mito sobre la edad de oro de la comunidad, en la cual los hombres eran más buenos y más sabios, y a partir de la cual el conocimiento verdadero habría sido transmitido generación tras generación sin cambios hasta el presente. El modo tradicional de legitimación de las creencias tiende así a vincular «lo verdadero» con lo recibido y opera sobre el supuesto de que el grado de validez de las creencias viene determinado, no por la fuerza de la lógica y el apoyo de los datos empíricos que obran a su favor, sino por su antigüedad. 
Recuerdo, no obstante, un pasaje en el que Hanson escribía: "Señalé una vez respecto de un científico ya mayor que habla tenido cuarenta años de experiencia. Un critico contestó que el individuo en cuestión no tenía la experiencia de cuarenta años; más bien tenía la misma experiencia una y otra vez, cuarenta ańos seguidos" (Hanson, 1971:23).

Efectivamente, Horton parece olvidar que cuando hablamos de la experiencia científica no nos referimos a la que se deriva de una actitud conformista hacia el corpus de conocimiento recibido y al amparo del cual se interpretan una y otra vez los acontecimientos sin dudar jamás de su validez. Cuando hablamos de la "experiencia científica" nos referimos solamente a un tipo de experiencia adquirida con el paso de los años, sino a la que ha sido extraída de una multiplicidad de situaciones especificamente disefiadas y rigurosamente controladas con el fin de obtener las pruebas necesarias para confirmar o refutar las creencias (o, cuando menos, conseguida a través de una observación rigurosa y sistemática). La experiencia científica, por tanto, no se puede obtener pasivamente. "Contrastar" es buscar esas pruebas de forma activa, y el hecho de que sean tenidas por relevantes para el mantenimiento de lo creido implica una concepción falible del conocimiento, una clara conciencia del carácter hipotético de los enunciados científicos y la disposición a no aceptar condescendientemente como verdadero aquello que sea contradictorio con la experiencia.

Ahora bien, para tratar un enunciado como si fuese una hipótesis, debe ser de un tipo tal que pueda recibir apoyo empírico y sobre todo que pueda fracasar empíricamente; esto es, que cuando se le proponga al mundo externo, éste pueda responder con un "no" a la afirmación que expresa el enunciado. A diferencia de Horton, algunos tenemos la impresión de que las expresiones mágico-religiosas no se formulan, por lo general, de manera que puedan exponerse a recibir un "no" del mundo externo (al menos de ese mundo externo objetivado de la ciencia), y en consecuencia pensamos que no se las trata como si fuesen hipótesis. Pero incluso en aquellos casos en los que las afirmaciones mágico-religiosas son susceptibles de recibir un "no" del mundo externo y de hecho lo reciben, éste no suele tener el impacto que tendría si esas expresiones estuviesen siendo tratadas como auténticas hipótesis. Ni siquiera cuando el "no" es evidente y pertinaz suele tener el poder suficiente para poner en tela de juicio las creencias que sustentan esa afirmación, presumiblemente porque la fuerza demostrativa del discurso mágico-religioso tradicional no reside, como antes sefialaba, ni en la lógica ni en la experimentación sino en la autoridad de 
los antepasados, contra la cual los criterios empíricos de la ciencia no pueden nada. Si tal impresión es correcta, si las afirmaciones mágico-religiosas nunca se ven afectadas por el "no" de la experiencia, habríamos de concluir que el recurso a la autoridad de los antepasados como medio de legitimación de las creencias que expresan esas afirmaciones no sólo difiere sustancialmente del modo de legitimación de las teorías científicas, sino que, al dejar excluida la posibilidad de su falsación, lo hace de hecho impracticable.

Si volvemos al caso zande, encontraremos que sus expresiones relacionadas con la Brujería tienen como referencia todo un universo de actitudes subjetivas, fuerzas sobrenaturales y poderes encantadores que, por su falta de contenido empíricamente contrastable, quedan en gran medida excluidas de cualquier universo de discurso científico. No obstante, hay otras afirmaciones del sistema de Brujería zande que podrían ser fácilmente contrastadas por los azande si respondiesen a intereses científicos o quasi-científicos, como las referentes a la transmisión de la materia de Brujería. Por ejemplo, la práctica de autopsias para determinar la presencia de la materia de Brujería en el vientre de los individuos es una comprobación empíricamente satisfactoria para saber si la hipótesis "el zande $\mathrm{x}$ es un brujo" es verdadera. Por lo cual, si los azande sintiesen la más mínima necesidad de determinar empíricamente la verdad de su creencia en la transmisión biológica de la brujería podrían zanjar este asunto de una vez por todas realizando autopsias sistemáticamente o al menos tomando en cuenta los resultados de aquellas que casualmente practican (algo que, según se desprende de la interpretación de Horton, los azande deben suponer que se ha venido haciendo desde hace mucho tiempo). Pero he aqui que, según se expresa Evans-Pritchard, la práctica de las autopsias deriva con frecuencia en resultados contradictorios, por lo que si los criterios cientificos realmente jugasen algún papel en todo esto, hace también mucho tiempo que los azande se habrian visto forzados a rechazar la validez de tal hipótesis.

¿Qué más le queda por hacer Robin Horton para convencernos de que no nos encontramos ante lo que parece ser un absoluto desinterés de los azande por la cuestión experimental? Horton (1976:174) dice que «los azande no pierden el tiempo en especulaciones desinteresadas acerca de qué clase de cosa sea la emanación de la Brujería en si misma... sino en lo que hace en el mundo observable» y añade que «En este sentido, su actitud hacia la Brujería, al igual que la de los científicos hacia sus entidades teóricas, es sumamente empírica, en realidad sumamente 'operacional'" (Ibid.). 
Pero a Horton le gusta pensar en la Brujería como si se tratase de una «entidad teórica inobservable» de tipo cientifico. Por eso desvia el discurso con habilidad hacia la inobservable "emanación de la Brujería" en lugar de centrarse en la relación entre la materia de Brujería y sus implicaciones más directamente contrastables. Sin embargo, por lo que respecta al tratamiento de las entidades teóricas, el ejemplo zande no guarda ninguna analogia con las actividad de los científicos. Como señalaba Salmon (pág. 450), la materia de Brujería es una sustancia orgánica localizada en el vientre de las personas, no es ninguna entidad teórica inobservable; los brujos son personas; y las acciones de los brujos son acciones de agentes humanos, o de su materia de Brujería, no son acciones de entidades inobservables. Así que, al menos en este terreno, no parece que los azande hubiesen de tener demasiados problemas para precisar cuáles son las operaciones que servirian para determinar sistemáticamente si se pueden encontrar regularidades empíricas mucho más fácilmente observables que aquellas que hacen referencia a la misteriosa "emanación de la Brujería".

Los azande, sin embargo, no actúan de esta manera, y en lugar de recurrir a la observación sistemática, cuando no a la experimentación, prefieren consultar a los oráculos todo aquello que les interesa de la Brujería. Asi que vayamos a los oráculos azande para ver ahí una vez más la falta de equivalencia entre el soporte de sus creencias y el de las teorías científicas.

Sabemos que el oráculo más fiable de los azande es el oráculo del veneno: "El oráculo del veneno no se equivoca, es nuestro papel'", suelen decir los azande (Evans-Pritchard, 1937:250). Pero, como sefiala Evans-Pritchard, resulta que "el oráculo del veneno parece estar organizado de tal modo que proporcione el mayor número de contradicciones evidentes" (pág. 300). Y así es, en efecto, pues, cuando se trata de cuestiones importantes, los azande no conceden validez a la prueba única, sino que requieren dos pronunciamientos coincidentes del oráculo para dar validez al veredicto. No obstante, los registros de Evans-Pritchard muestran sin lugar a dudas que cuando se realiza doble prueba el oráculo se contradice aproximadamente el mismo número de veces que no se contradice (v. esp., págs. 303- 308).

Dado que el oráculo del veneno es considerado una fuente segura de verdad ${ }^{19}$, nos preguntamos cómo explican los azande sus contradicciones.

19 "El oráculo de los venenos no yerra', es el credo de todos los azande* (pág. 135). 
Evans-Pritchard agrupa en ocho clases las respuestas que le proporcionaban los azande: «1) la mala variedad del veneno que se ha recolectado, 2) el incumplimiento de algún tabú, 3) la Brujería, 4) la ira de los propietarios del bosque en que crecia la enredadera [de la cual se extrae el veneno], 5) la antigüedad del veneno, 6) la ira de los espíritus, 7) la hechicería, y 8) la utilización" (pág. 308). Mediante la apelación a una u otra de estas causas, los azande consiguen justificar cada veredicto contradictorio del oráculo de manera inmediata. Pero notemos que cada veredicto contradictorio afecta únicamente a la indecisión de un caso concreto, y ya que los azande nunca registran sistemáticamente estos casos, jamás puede ocurrir que la acumulación de contradicciones sirva para poner en cuestión la validez del oráculo mismo.

Nos preguntamos, por último, qué dicen los azande cuando el oráculo pronostica que pasará una cosa y después sucede otra distinta, ¿arroja esto alguna duda sobre su validez? Pues, no. Más bien, a la inversa, los fallos del oráculo del veneno les sirven para reforzar su creencia en las demás fuerzas misteriosas, pues no sólo "los errores así como los juicios válidos... les demuestran su infalibilidad" sino que "El hecho de que el oráculo se equivoque cuando es interferido por algún otro poder misterioso demuestra cuán exactos son sus juicios cuando se excluyen esos poderes" (pág. 308).

Con estos datos en la mano, cualquiera daría por cerrada la cuestión, pues se hace evidente que las creencias azande no resultan falsables para los azande bajo ninguna circunstancia imaginable $y$, consiguientemente, deberíamos admitir que su validación no tiene nada que ver con los criterios empíricos de la ciencia. Fue esta misma falta de exposición de las predicciones del oráculo a la falsación la que llevó a Peter Winch a decir que las expresiones azande relacionadas con la Brujería y los oráculos no son tratadas como auténticas hipotesis y de ahl extrajo la conclusión de que las creencias azande no operan a un nivel teórico equivalente al de la ciencia. Por eso argumentaba que

«El espíritu con el que se consultan los oráculos es muy diferente al de los cientificos cuando hacen sus experimentos. Las revelaciones de los oráculos no son tratadas como hipotesis, y puesto que su sentido deriva del modo en que se las trata en su contexto, en consecuencia no son hipótesis... Si el oráculo revela que un curso de acción que se le ha propuesto está lleno de peligros misticos de Brujería y hechicería, ese curso de acción no se lleva a cabo, y entonces el problema de la refutación o confirmación no se produce. podríamos decir que la revelación tiene el estatus lógico de un hipotético no actualizado, si no fuese 
porque el contexto en el cual se emplea este término lógico puede sugerir de nuevo una analogia errónea con las hipótesis cientificasm (Winch, 1964:88).

He aquí, por el contrario, lo que opina Horton al respecto:

"... a pesar de lo que dice Winch, hay muchas ocasiones en las que, durante el curso de su vida diaria, los azande ponen a prueba las consecuencias empiricas predichas por sus creencias místicas: como, por ejemplo, cuando los oráculos les han dicho que las medidas tomadas han eliminado los obstáculos de su camino, y que por lo tanto pueden seguir adelante libremente con sus planes previstos. En tales ocasiones, ellos son cualquier cosa menos indiferentes a la relación entre las predicciones generadas por sus creencias y la experiencia subsiguiente. Si tales predicciones son confirmadas por la experiencia, ellos senalan este hecho con satisfacción como prueba de la corrección de la revelación oracular original y de la eficacia del oráculo del veneno. Si las predicciones son refutadas, buscan inquietamente las razones: e.g. los hechiceros que interfieren las revelaciones o el veneno del oráculo que se ha echado a perder. De nuevo aqui, nos encontramos todavia en un mundo que no es notablemente distinto del mundo de los cientificos" (1976:148).

A tenor de lo visto anteriormente, parecerla más acertado decir que, de nuevo aqui, nos encontramos todavia con un mundo notablemente distinto al mundo de los científicos. pues no hay nada que nos invite a pensar que los azande "ponen a prueba" sus creencias místicas y ni siquiera a sospechar que consideren los datos empíricos como elementos relevantes para el mantenimiento de lo creído ${ }^{20}$. Más bien, al contrario, cuando un zande acomete una empresa con el visto bueno del oráculo, si tal empresa fracasa, él siempre cuenta con alguna otra creencia, todavia más incontrastable que la anterior, que justifica el fallo del oráculo sin atender a la experiencia. Así, suceda lo que suceda, la veracidad del

20 Es evidente que los recursos empleados por los azande para justificar los fallos de los oráculos no son siquiera meras hipótesis ad hoc, como parece insinuar Horton en el párrafo citado, sino respuestas estereotipadas que se repiten una y otra vez sin que puedan llegar a ser ellas mismas cuestionadas en ningún momento. Sin embargo, los azande actúan experimentalmente sobre aquellos aspectos del oráculo que les interesan especialmente. Por ejemplo, tras obtener el veneno en el bosque, verifican su calidad observando si unas aves mueren y otras sobreviven bajo su influencia; si todas mueren o todas sobreviven, los azande desechan el benge (v. Evans-PRTCHARD, 1937:308,313). Esto indica que los azande saben bien que datos empíricos son relevantes para el mantenimiento de sus creencias y cuáles no lo son, pero indica también que su relevancia no se mide por los criterios de la ciencia occidental. 
oráculo está permanentemente garantizada y con ella lo están las demás creencias relacionadas con la Brujería, por lo que nunca puede haber tal refutación. En estas circunstancias el sistema no puede fallar.

\section{Juegos y convenciones}

Dado que a visto la luz de los criterios utilizados por la ciencia occidental todo esto resultaría un modo perverso de poner a salvo las creencias ante cualquier posible conflicto con la experiencia, podríamos sentirnos tentados a suponer con Mary Douglas (1966:208209) que nos hallamos ante una estratagema generalizada en los contextos tradicionales, merced a la cual umuchas religiones primitivas, que con una mano prometen el éxito material, con la otra se protegen contra la cruda experiencia..." ${ }^{21}$. Probablemente Mary Douglas tenga una buena parte de razón en lo que dice. De cualquier manera, si admitimos que los criterios de la racionalidad científica no tienen por qué ser universalmente compulsivos podemos aceptar que esos sistemas de pensamiento operan de acuerdo con unas convenciones propias y ajenas a las que se aceptan en el ámbito científico. Diríamos, entonces, que se trata de juegos diferentes, entendiendo «juego" en el sentido extenso que desde Wittgenstein se viene otorgando a este término en la filosofia contemporánea. No obstante, Emily Martin Ahern (1982) ha comparado las consultas oraculares de los azande con las actividades occidentales a las que llamamos propiamente juegos en el lenguaje ordinario, como el ajedrez, los naipes o los deportes, y ha encontrado buenas razones para pensar que las preguntas que Evans-Pritchard realizaba a los azande estaban completamente fuera de lugar, pues no encajaban dentro de sus reglas constitutivas. Como señala Ahern, es tan absurdo preguntarle a un zande qué ocurriráa, por ejemplo, si se le administrasen varias dosis de veneno a un mismo pollo como lo es sugerir a un jugador de tenis la posibilidad de situarse en un lateral de la pista para efectuar su saque, o como lo es insinuar a un jugador de ajedrez que podría hacer escapar a su rey de un jaque mate moviéndolo dos escaques al frente y tres hacia la derecha para dejar asi en jaque mate al rey del oponente. $\mathrm{Si}$ alguien nos hiciese estas propuestas seguramente supondriamos que no ha

21 Douglas señala expresamente que «Un modo de proteger el rito contra el escepticismo» consistente ken suponer que un enemigo, dentro o fuera de la comunidad, se dedica constantemente a deshacer sus buenos efectosn (Op. cit. :206-207), algo que, después de lo visto con los azande, ya nos resulta bastante familiar. 
entendido en qué consiste el juego en cuestión ni que cualquier intento de pasarlas por alto implica la renuncia a seguir jugando.

Ahern tiene razón en todo esto. Después de haber insistido repetidas veces en que tales movimientos no entran dentro de los límites que definen la práctica del juego, lo más probable es que tanto los azande como cualquiera de nosotros acabásemos por reprochar al impertinente sugeridor la estupidez de sus propuestas. Pero Ahern olvida mencionar que, por extensión, también la ciencia puede ser considerada una especie de juego reglamentariamente constituido, aunque sus reglas sean muchas, complejas y no siempre se muestren de forma explicita. Ya he apuntado repetidamente que, sea cual sea la disposición particular de los científicos a someter sus teorías a la crítica pública, hemos de suponer que es su compromiso asumido con los criterios imperantes en la práctica científica lo que les impulsa, cuando se les cuestiona sobre la conformidad de sus teorlas con dichos criterios, a buscar respuestas adecuadas para satisfacerlos, pues en otro caso quedarian excluidos de participar en este juego. Por eso, el hecho de que los azande encontrasen estúpidas las cuestiones, objeciones y desafíos planteados por Evans-Pritchard, quien actuaba desde el punto de vista de un europeo mediatizado por los criterios del juego de la ciencia, tiene un claro y potente efecto negativo sobre la tesis de Robin Horton al demostrar que los azande no los encuentran aplicables a sus creencias. De haber sentido ellos la más mínima necesidad de ajustar sus creencias a los criterios de validación de las teorías científicas, al menos se habrían molestado en buscar respuestas adecuadas para satisfacer las exigencias de Evans-Pritchard. Pero no siendo así, habremos de concluir que no están jugando al «juego de la ciencia" y en consecuencia tonaremos que renunciar a la pretensión de que sus creencias y las teorías de la ciencia puedan ser neutralmente evaluadas.

\section{Referencias bibliográficas}

AHERN, E. M. (1982): “Rules in Oracles and Games». Man, n.s., 17: 302-312.

BLOOR, D. (1976): Knowledge and Social Imagery. Londres: Routledge \& Kegan Paul. 2.2 ed. 1991, en Chicago: Chicago University Press, cap. 7.

COOPER, D. E. (1975): "Alternative Logic in 'Primitive Thought'", Man, n.s., 10: 238-256.

Douglas, M. (1966): Pureza y Peligro;. Un analisis de los conceptos de contaminación y tabú. Madrid: Siglo XXI, 1973. 2.2 ed. 1991. 
EVANS-PritchaRD, E. E. (1937): Brujeria, magia y oráculos entre los azande, Barcelona: Anagrama, 1976.

EVANS-PrITCHARD, E. E. (1965): Las teorias de la religion primitiva. Madrid: Siglo XXI, 1973. 7.2 ed. 1990.

Hanson, N. R. (1971): «Observación y explicación». Patrones de descubrimiento. Observación y Explicación. Madrid: Alianza Editorial, 1977. 2.a ed. 1985.

Hanson, N. R. (1967): "African Traditional Thought and Western Science». Africa, 37: 50-71 (parte I: «From Tradition to Science»); 155-187 (parte II: «The 'Closed' and 'Open' Predicamentes").

HORTON, R. (1976): «Professor Winch on safari». European Journal of Sociology vol. 17; reimp. en R. HORTON 1993: 138-160.

HORTON, R. (1979): «Material-object Language and Theoretical Language: Towards a Strawsonian Sociology of Thoughtm, en S. C. Brown (ed.), Philosophical Disputes in the Social Science. Brighton: The Harvester Press, 197-224.

HORTON, R. (1982): "Tradition and Modernity Revisited", en M. Holus y S. LUKES (eds.), Rationality and Relativism. Oxford: Blackwell, 201-260.

HORTON, R. (1993): Patterns of thought in Africa and the West. Essays on magic, religion and science. Cambridge: Cambridge University Press.

QUINE, W. O. (1953): "Dos Dogmas del Empirismo", en Luis M. L. VALDES VillanUeVa (ed.), La bisqueda del significado. Madrid: Tecnos y Universidad de Murcia, 1991: 220-234.

QUINE, W. O. (1959): “Significado y Traducción”, en Luis M. L. VALDES VILANUEVA (ed.), La brisqueda del significado. Madrid: Tecnos y Universidad de Murcia, 1991: 244-269.

QUINE, W. O. (1970): Filosofia de la logica. Madrid: Alianza Universidad, 1973.

QUINE, W. O. (1990): La búsqueda de la verdad. Barcelona: Crítica, 1992.

Salmon, M. H. (1978): "Do Azande and Nuer Use a non-Standard Logic?". Man, n.s., 13: 444-454.

Searle, J. R. (1965): trad. española "¿Qué es un Acto de Habla?", en Luis M. L. VAlDEs Villanueva (ed.), La bisqueda del significado. Madrid: Tecnos y Universidad de Murcia, 1991: 431-438.

SKORUPSK, J. (197): «Science and Traditional Religious Thought». Philosophy of the Social Sciences, 3: 97-115; 209-230.

WINCH, P. (1959): The Idea of a Social Science and its Relation to to Philosophy. Londres: Routledge \& Kegan Paul, 2.2 ed. 1960.

WINCH, P. (1964): «Understanding a Primitive Society». Ameritan Philosophical Quarterly 1; reimp. en Bryan R. Wilson (ed.) 1970, Rationality Oxford: Blacwell, 78-111. 